\title{
Does the 2007 Noto Hanto earthquake reveal a weakness in the Japanese national seismic hazard map that could be remedied with geological data?
}

\author{
Shinji Toda and Yasuo Awata \\ Active Fault Research Center, Geological Survey of Japan, AIST, site 7, 1-1-1 Higashi Tsukuba, Ibaraki 305-8567, Japan \\ (Received June 29, 2007; Revised February 12, 2008; Accepted February 25, 2008; Online published November 7, 2008)
}

\begin{abstract}
The Noto Hanto earthquake struck one of the lowest earthquake probability regions on the national seismic hazard map of Japan. To contribute to future updates of the hazard map, we examined the predictability of the 2007 earthquake on the basis of geological data that were available before it occurred. Sonic prospecting profiles of active faulting and the absence of an onshore fault could have limited the potential rupture length to $12-15 \mathrm{~km}$, similar to the 2007 source. Empirical relationships between magnitude and fault length would have given us $M_{\mathrm{j}}=6.6-6.8$ and $M_{\mathrm{w}}=6.3-6.4$. The emergence of one marine terrace, which inclines to the south and reaches an altitude of approximately $50 \mathrm{~m}$, can be dated to 120-130 ka and yields an uplift rate of approximately $0.4 \mathrm{~mm} /$ year. $M_{\mathrm{w}}$-displacement empirical relationships and examples of recent blind fault events that have occurred at various locations around the world suggest that the conceivable maximum coseismic uplift of such shocks is $40-70 \mathrm{~cm}$. Together with the uplift rate, we would have obtained an average recurrence interval of 1000-2000 years and, consequently, a 1.5-3.0\% time-independent (Poisson) probability for 30 years. In addition, the significant inclination of the marine terraces-3.2 per mille $(0.32 \%)$ - is better explained by the accumulation of frequent southward tilting as large as that of the 2007 type event with approximately 1600-year intervals, without any significant contributions from other seismic sources. We therefore conclude that the Noto Hanto earthquake source would have been better evaluated and identified if we had taken into account not only major active faults but also the active tectonics of moderate-size faults and their associated scale and rate.
\end{abstract}

Key words: Noto Hanto earthquake, blind thrust, earthquake probability, seismic hazard map, long-term earthquake forecasting.

\section{Introduction}

The Earthquake Research Committee of the Headquarters for Earthquake Research Promotion (subsequently referred to as ERC), a special governmental organization of Japan, released the probabilistic national seismic hazard maps in March 2005. These are based on 10 years of intensive surveys of paleoseismic trenches, drillings, and seismic recordings and the assemblage of existing seismic and geological data dating from after the 1995 Kobe shock (Fig. 1; ERC, 2005). Because of the short recurrence times and time-dependence of subduction earthquakes (e.g. the next Tokai earthquake is considered to be imminent), the coastal regions facing the Pacific Ocean have high probabilitieshigher than $26 \%$ in the next 30 years-of experiencing earthquakes with JMA seismic intensity $\left(I_{\text {jma }}\right) \geq$ VI (equivalent to MMI X-XI) or lower. In contrast, inland regions, such as those facing the Japan Sea, have the lowest probabilities due to the infrequent activity of shallow, large active faults. In fact, one may argue that the ERC forecasting map has already failed because several recent destructive earthquakes, recorded at $I_{\mathrm{jma}} \geq \mathrm{VI}$, or lower, have struck the lower probability areas along the Japan Sea (Fig. 1). The

Copyright (c) The Society of Geomagnetism and Earth, Planetary and Space Sciences (SGEPSS); The Seismological Society of Japan; The Volcanological Society of Japan; The Geodetic Society of Japan; The Japanese Society for Planetary Sciences; TERRAPUB
2007 Noto-Hanto earthquake is one such example.

The national hazard map is largely based on the maximum size of regional earthquakes and their frequencies, focusing on subduction zones and major active faults longer than $20 \mathrm{~km}$. In terms of predicting the frequency of destructive earthquakes, the map displays the fundamental weakness of the ERC's evaluation system because it ignores short-length active faults inland that are associated with active folds, crustal tilting, and ocean bottom active faults near coastlines. In order to revamp the evaluation system to incorporate such minor and faint but numerous shallow earthquake sources, it is important to use all existing geological data available.

In this paper, we first review the mechanism of the source fault of the Noto Hanto earthquake. We then seek correlations with active geological and geomorphological features and retrospectively forecast the Noto Hanto earthquake, estimating its magnitude, recurrence interval, and probability.

\section{Overall Relationship between Geological Structure, Source Fault, and Aftershocks}

From north to south, the Noto Peninsula is composed of the NE-trending Oku-Noto Hill, N-trending Chu-Noto Hill, and NE-trending Sekido Range (Fig. 2). This range and hills are composed of inclined crustal blocks bounded by transverse geological faults and offshore and inland NE- 


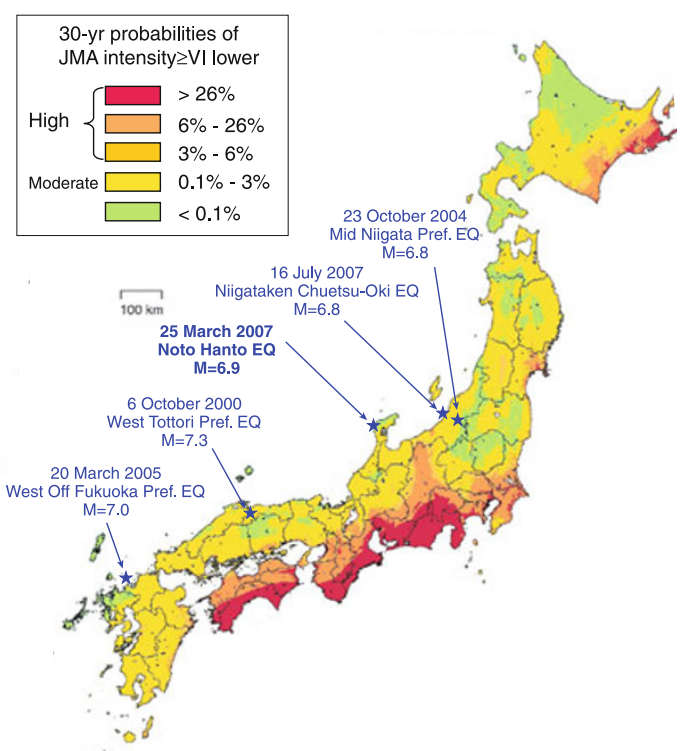

Fig. 1. Probabilistic seismic hazard map of Japan for strong ground motion of JMA intensity = VI lower and greater for the next 30 years starting from 2005 (Earthquake Research Committee of the Headquarters for Earthquake Research Promotion, 2005), and recent destructive shallow earthquakes recorded by JMA with intensity $\geq$ VI or lower. Note that all five shocks occurred where the 30-year probabilities are lower than $3 \%$; the 2007 Noto Hanto earthquake struck in one of the lowest earthquake probabilistic regions.

trending faults that have been active since the late Tertiary period (e.g. Ota and Hirakawa, 1979). WNW-oriented compressional strain detected by the GPS networks (Sagiya et al., 2000) provides evidence of the driving force for both $\mathrm{NE}$ - and N-trending faults despite the low strain rate relative to the other regions in Japan. The 2007 Noto Hanto earthquake occurred at the structural junction of the OkuNoto and Chu-Noto Hills. The fault plane solution of the Noto Hanto earthquake (JMA, 2007; NIED, 2007; USGS, 2007) suggests that the earthquake was caused by a steeply dipping reverse fault with a right-lateral component, which is consistent with a slip oblique to the maximum compressional stress axis. The aftershock distribution within the first day, which generally shows a source fault dimension, suggests an approximately $15-\mathrm{km}$-long reverse fault (Fig. 1).

The onshore region is mainly underlain by the Miocene sedimentary and volcanic rocks (Geological Survey of Japan, 1992). Although there are approximately 2-kmwavelength NE-trending folds (Geological Survey of Japan, 1967), no evidence is currently available indicating either the presence of active folds or mapped faults associated with the eastern part of the 2007 source (Ota et al., 1976; Research Group for Active Faults in Japan, 1991). In contrast, Okamura (2003) and Katagawa et al. (2005) reported the presence of several active faults in the offshore region from their sonic prospecting surveys west of the Peninsula. Katagawa et al. (2005) in particular detailed a couple of NEtrending inclined and uplifted blocks bounded by a group of

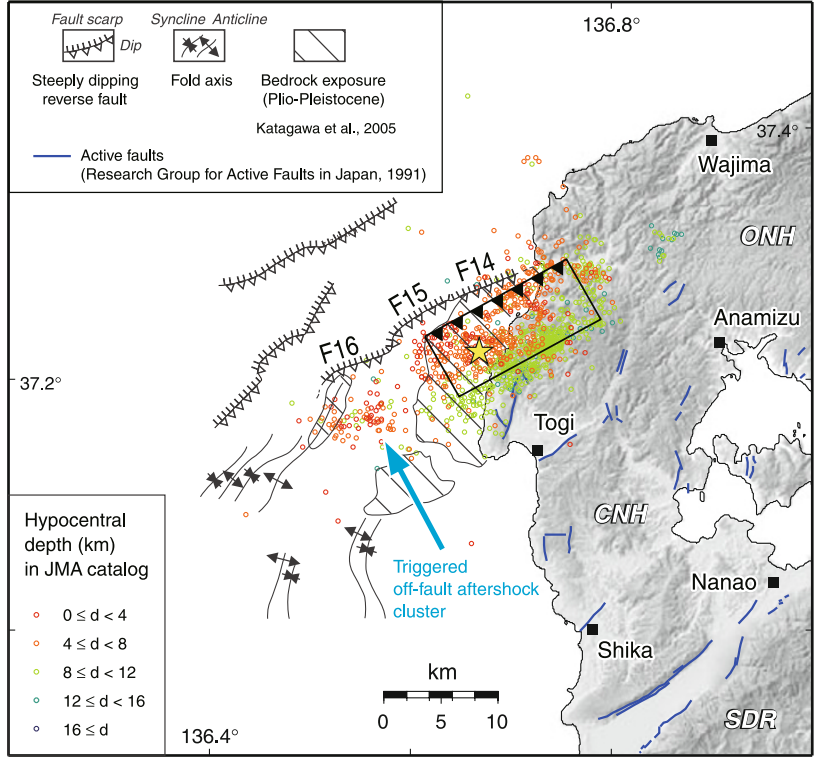

Fig. 2. Noto Hanto aftershocks within the first $24 \mathrm{hr}$, and mapped active structure on and off the Noto Peninsula. Star denotes the epicenter. Thick black square with teeth marks is the surface projection of the source fault modeled by Awata et al. (2008). Aftershocks are from JMA PDE catalog. ONH, Oku-Noto Hill; CNH, Chu-Noto Hill; SDR, Sekido Range.

active faults, a part of which corresponds to the mainshock and aftershock zone of the Noto Hanto earthquake. Following a detailed correlation study between onshore geology and acoustic stratigraphy, these researchers interpreted the tilted block as originating in the Neogene Tertiary to upper Quaternary. Based on fault linearity, discontinuity, and the timing of the most recent movements, they subdivided the block bounding the fault into three sub-faults, F14, F15, and F16, and active folds further west (Fig. 2). They also speculated that the sub-fault F14 possibly offset the lower Holocene but is terminated by the upper Holocene, whereas the sub-faults F15 and F16 show no deformation of both Holocene periods and even older strata formed during the last glacial period. The aftershock zone within the first $24 \mathrm{hr}$, which is often used as a proxy for the source fault area, corresponds to the sub-fault F14 and eastern half of F15 (Fig. 2). Thus, paleoseismic evidence explains why the rupture of the Noto Hanto earthquake stopped roughly between sub-faults F14 and F16.

\section{Source Constraint and Repeatability: Rela- tionship between Coseismic Vertical Displace- ment and Long-term Deformation}

The Noto Hanto earthquake caused significant coseismic crustal uplift (Geographical Survey Institute (GSI), 2007). Coastal uplift across the epicentral zone was visible after the earthquake and provided information that was more useful in determining the coseismic deformation than that recorded by the sparsely distributed GPS stations (note that InSAR analysis by GSI provides the best coseismic deformation, but it took about 2 weeks after the mainshock to obtain this analysis). Awata et al. (2008) measured the uplift on a preseismic shoreline composed of an emerged oys- 


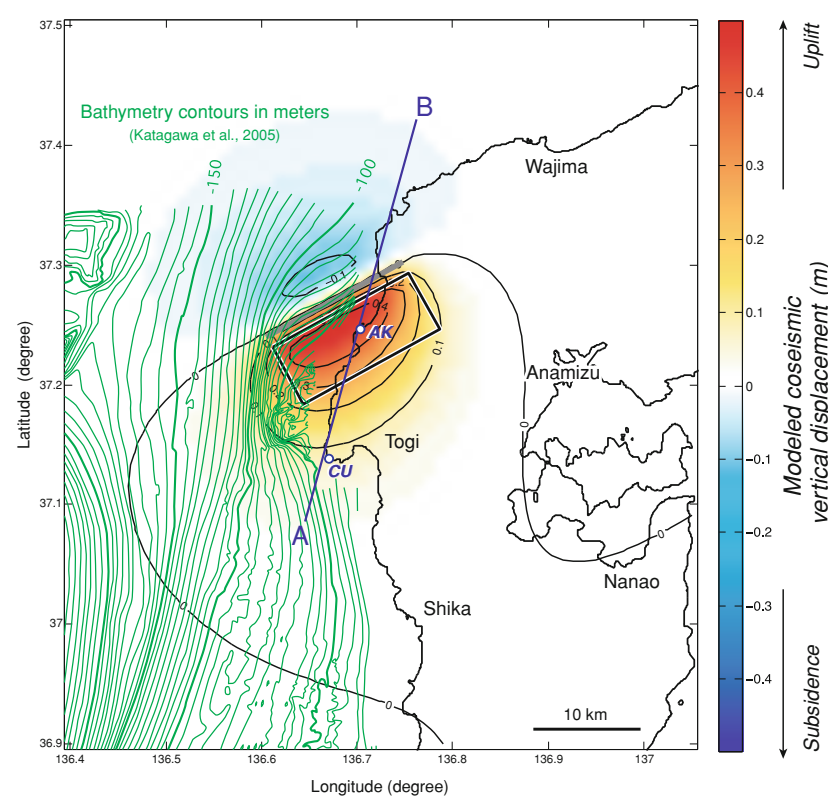

Fig. 3. Map showing a superb agreement between the western margin of the coseismically uplifted dome (gradational color) and curved bathymetric contours (green lines, with 5-m contour interval) formed by the protruded shelf atop the Noto Hanto source fault. The source fault is the black-lined rectangle. The blue A-B line is for a cross section shown in Fig. 4. AK and CU are Akakami and Chinoura, respectively, used for discussion in text.

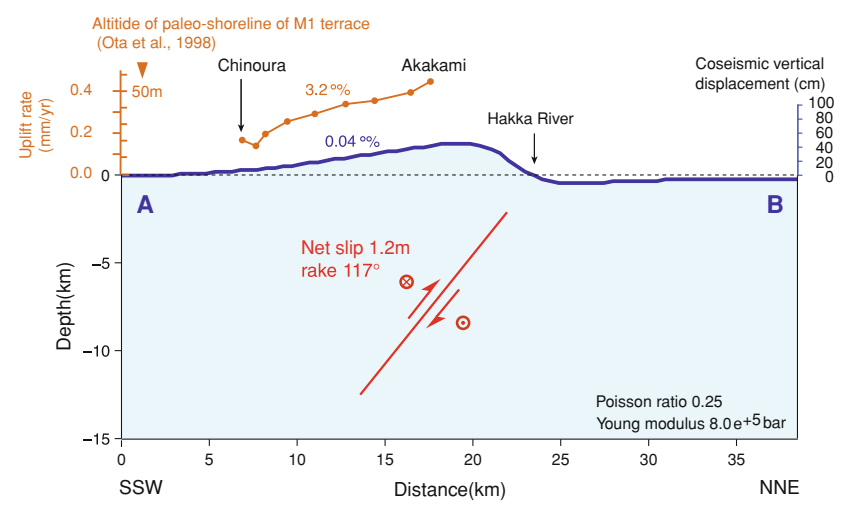

Fig. 4. Deformation profile of coseismic vertical displacement of the 2007 event (blue) and the former shoreline of the M1 terrace (orange) along the coastline (azimuth $\mathrm{N} 16^{\circ} \mathrm{E}$ ) that crosses the 2007 source fault. Coseismic deformation due to the 2007 event is calculated from a source fault model by Awata et al. (2008) that is denoted by red text and red lines. The marine terrace M1 resembles the coseismic deformation.

ter assemblage, algae, and other inter-tidal species along an approximately 50-km-long coastline between Wajima and Hakui. A maximum uplift of approximately $40 \mathrm{~cm}$ was measured between Tsurugiji and Akakami, 3-5 km NE of the epicenter, and a small subsidence of less than several centimeters was located between Fukami and Yoshiura, 13$17 \mathrm{~km}$ northeast of the epicenter. To explain the observed large uplift and the faint subsidence, these researchers modeled a steeply dipping blind reverse faulting that generates an asymmetric folding pattern at the Earth's surface. The spatial pattern shows a NE-trending concentric elliptic dome. Together with the bathymetric contours drawn by Katagawa et al. (2005), we found that the contour curva- tures coincide with the westward convex shape of the coseismic uplift contours (Fig. 3). In other words, the coseismically uplifted area indeed corresponds to the widely distributed shallow shelf protruding to the west from the coastline. We believe this is not a coincidence but instead suggests that similar repeated earthquakes built the shallow shelf atop the 2007 source. The sonic prospecting profiles also furnish evidence that the uplifted shelf exposes Miocene and Paleogene Tertiary bedrocks (Katagawa et al., 2005).

A widely distributed emerged marine terrace provides another source of compelling evidence for the repeatability of the 2007-type events. Ota (1975) and Ota et al. (1998) classified and mapped several stages of marine terraces and measured the former shorelines on the Noto Peninsula. The ages of the terrace groups are mostly unconstrained due to scanty dating material. However, the most widely and well-preserved M1 marine terrace is confirmed to have been formed during the maximum transgression of the Last Interglacial stage (marine oxygen isotope stage 5e), dated 120$130 \mathrm{ka}$. In and around the epicenter, the distribution of the M1 terrace is almost continuous from Akakami to Togi (Ota et al., 1998). Altitudes of the former shorelines associated with the M1 terrace decrease from approximately $50 \mathrm{~m}$ at Akakami to approximately $20 \mathrm{~m}$ at Chinoura (Fig. 4). Since the older shorelines show greater height differences between Akakami and Chinoura, as Ota (1975) suggested, the block-tilting movement may have been continuous from the late Tertiary to the last interglacial stage, which is consistent with the speculation from offshore geology (Katagawa et al., 2005). Coseismic coastal uplift due to the Noto Hanto earthquake shows a similar pattern of southward inclination along the coastline from Akakami to Chinoura (Awata et al., 2008). Since the approximately 3.2 per mille slope of the M1 terrace is so steep, it is unlikely that other distant and large events have produced such significant tilting. Also, because the M1 landform can be simply built by successive 2007-sized coseismic uplifts, we interpret the 2007 Noto Hanto earthquake to be a characteristic event in this region and infer that earthquakes of its size and mechanism were the main contributors to the block uplift and inclination of the terraces.

\section{Retrospective Forecasting Magnitude, Recur- rence Time, and Probability}

We assume that the magnitude of the Noto Hanto earthquake would have been evaluated from existing geological data even though there was no known remarkable active fault mapped prior to the earthquake (e.g. Research Group for Active Faults in Japan, 1991). As described above, fault F14 (discovered by Katagawa et al., 2005) underlies the shelf to the coastline, with a length estimated to be 12$15 \mathrm{~km}$ (F14 is measured to be as long as $12 \mathrm{~km}$ in their paper, but due to the linearity between F14 and F15, most of fault F15 may be connected to F14, which extends the length to $15 \mathrm{~km}$ ). If one had applied an empirical relationship between the $M_{\mathrm{j}}$ and fault length (Matsuda, 1975), the expected $M_{\mathrm{j}}$ would have been 6.6-6.8. If the Wells and Coppersmith (1994) formulae on $M_{\mathrm{w}}$ and subsurface rupture length for reverse fault had been used, we would have 

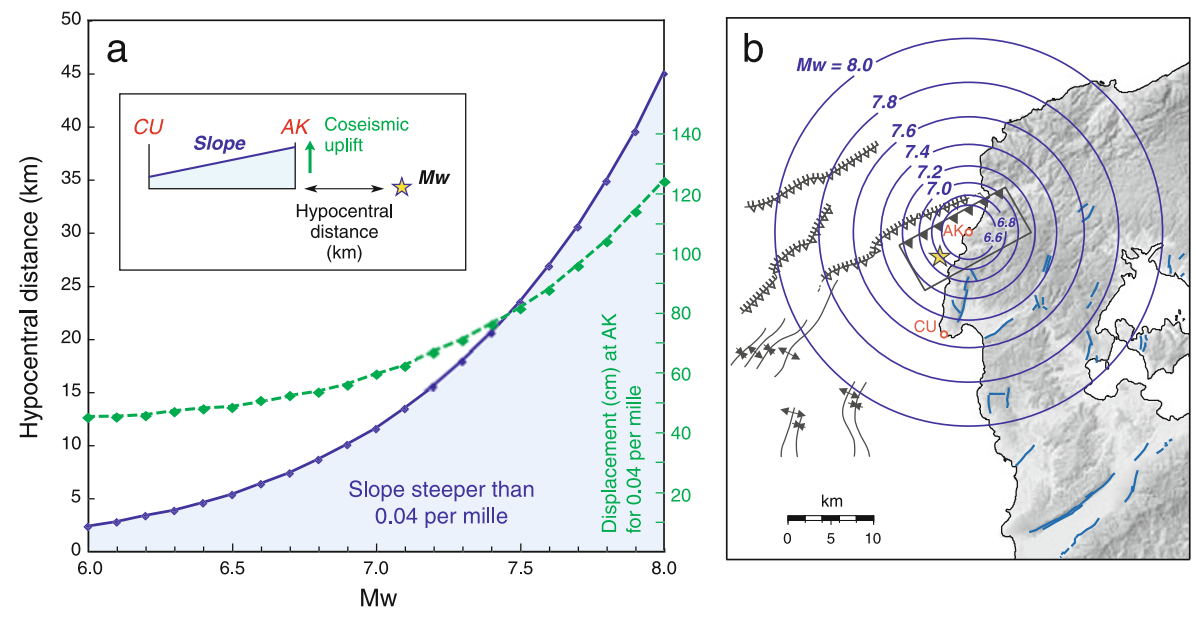

Fig. 5. All possible seismic sources that could have tilted the marine terraces in late Quaternary. (a) Hypocentral distance and $M_{\mathrm{w}}$ to reproduce a coseismic tilt steeper than 0.04 per mille $(0.004 \%)$ between two locations separated by $11 \mathrm{~km}$ in an elastic half space. The light-blue area indicates the conditions for such a steep slope. (b) Theoretical locations of seismic sources and $M_{\mathrm{w}}$ to satisfy the conditions in (a). See Fig. 2 for geological legend.

an estimated $M_{\mathrm{w}}$ of 6.3-6.4. Because the Wells and Coppersmith formulae are derived using a global dataset obtained from different tectonic settings, we believe that the application of these formulae may slightly underestimate reverse faults in Japan. Further, the length of subsurface rupture is generally longer than that of a surface fault. In any case, both estimates are slightly smaller than the 2007 event but comparable in terms of earthquake damage and strong ground motion.

Assuming the characteristic earthquake hypothesis (Schwartz and Coppersmith, 1984) under stable tectonic loading, a combination of coseismic displacement $D(\mathrm{~mm})$ and long-term slip rate $S$ (mm/year) allows us to estimate an average recurrence interval $T_{r}$ (year) using the following simple equation (Wallace, 1970)

$$
T_{r}=\frac{D}{S} \text {. }
$$

Although it is impossible to measure $D$ for a blind thrust fault, we suppose there are two possible approaches to estimating $D$ beforehand. The first approach is to implement an empirical relationship between $M_{\mathrm{w}}$ and $D_{\max }$ for reverse faults associated with the recent earthquakes around the globe (table 2B in Wells and Coppersmith, 1994). Had we considered $M_{\mathrm{w}}=6.3-6.4$, we would have obtained $D_{\max }=$ 97-104 cm from the following equation,

$$
\log \left(D_{\max }\right)=-1.84( \pm 1.14)+0.29( \pm 0.17) M_{\mathrm{w}} .
$$

A caveat of this approach is that the variance from the regression curve for $M_{\mathrm{w}}$ and $D_{\max }$ shown in parentheses is fairly large (see also figures 10 and 11 in Wells and Coppersmith, 1994). $M_{\mathrm{w}}=6.3-6.4$ may consequently introduce a large range of $D_{\max }$ values $(1 \mathrm{~cm}$ to $175 \mathrm{~m})$ and, therefore, considerable errors. In reality, for reverse faults, since $D_{\max }$ represents net slip, it is necessary to convert the net slip to vertical displacement with conceivable dip angles. If we simply opt for a range of dip angles between $30^{\circ}$ and $60^{\circ}$ we obtain vertical displacement $D U_{\max }=49-$ $90 \mathrm{~cm}$. The second approach is to directly approximate $D$ from examples of similar blind thrust events. Several recent well-recorded earthquakes ranging from $M_{\mathrm{w}} 6.5$ to 6.7 caused a maximum coseismic uplift of roughly $50 \mathrm{~cm}$. For example, leveling surveys across the epicentral area of the 2004 mid-Niigata prefecture (Japan) earthquake $\left(M_{\mathrm{j}}=6.8\right.$, $\left.M_{\mathrm{w}}=6.6\right)$ shows approximately $70 \mathrm{~cm}$ of maximum uplift at the anticline axis (GSI, 2004). The $1983 M_{\mathrm{w}}=6.5$ Coalinga (California) earthquake recorded a vertical displacement of as much as $50 \mathrm{~cm}$ (Stein and Ekstrom, 1992). The $1994 M_{\mathrm{w}}=6.7$ Northridge (California) earthquake upraised the Santa Susana Range over $40 \mathrm{~cm}$ (Hodgkinson et al., 1996). Thus, we could have empirically assumed that a blind thrust event raised the Earth's surface 40-70 cm at most. For the Noto Hanto case, using an uplift rate $S$ of $0.4 \mathrm{~mm} / \mathrm{year}$ at Akakami and Tsurugiji (Fig. 3) and a conceivable coseismic vertical displacement of 40-70 cm, which is typical for a blind thrust, we could have obtained an average recurrence interval $T_{r}$ of 1000-2000 years.

The uplifted M1 terrace with a slope of 3.2 per mille also supports the frequent occurrence of a Noto Hanto-type event that consequently produced a slope of 0.04 per mille (approx. $40 \mathrm{~cm} / 11 \mathrm{~km}$ ). Assuming the 2007 event is indeed characteristic, to contribute to the significant block tilting, one can estimate approximately 80 events since the last interglacial stage (approx. $125 \mathrm{ka}$ ) simply dividing 3.2 per mille by 0.04 per mille. This yields an average inter-event time of approximately 1600 years, which is consistent with that inferred from the uplift rate. However, one may argue that other possible sources could have contributed to the tilting. Here, we theoretically examine how large and how far other possible sources should be located to produce a slope steeper than 0.04 per mille using the equation (Okada, 1992)

$$
\log U_{\mathrm{ave}}=1.5 M_{\mathrm{w}}-2 \log R-6.6,
$$

where $U_{\text {ave }}(\mathrm{cm})$ is the expected average displacement due to an earthquake of moment magnitude $M_{\mathrm{w}}$ at the hypocentral distance $R(\mathrm{~km})$. Considering the maximum difference in simulated $U_{\text {ave }}$ at both Akakami (AK) and Chinoura 
(CU), we can examine the slope angle as a function of $M$ and $R$. To obtain a slope as steep as 0.04 per mille, for example, sources of $M_{\mathrm{w}}=6.6,7.0$, and 7.4 should be located closer than 6, 12, and $20 \mathrm{~km}$, respectively (Fig. 5(a)). Since no such long faults within 10-20 km of Akakami actually exist (Fig. 5(b)), we can rule out the possibility that other seismic faults contribute directly to the production of the tilted M1 terrace. If remote large earthquakes had contributed to the uplift itself, but not the tilting, the inter-event time of the Noto Hanto type should be shorter than approximately 1600 years to maintain the slope.

Since we do not have any reliable paleoseismic information on the most recent large earthquake in the epicentral area, we cannot calculate a time-dependent conditional probability. However, assuming the characteristic earthquake hypothesis, $T_{r}=1000-2000$ years, allows us to calculate a $1.5-3.0 \%$ time-independent (Poisson) probability for 30 years, which is comparable to the probabilities associated with the most active faults defined by ERC (compare: one quarter of the all known major active faults in Japan have time-dependent probabilities larger than $3 \%$ ).

\section{Discussion and Conclusion}

The source fault of the March 25, 2007 Noto Hanto earthquake is located beneath both onshore and offshore portions of the northwest Noto Peninsula. No obvious onshore surface rupture accompanied the earthquake, but a significant vertical coseismic uplift of up to $40 \mathrm{~cm}$ was involved. Inland and off-shore geological data, ocean bottom topography, and uplifted marine terraces provide us with clues that enable us to retrospectively forecast the location of the source, the possible magnitude of the earthquake, and the recurrence interval (= earthquake probability). An up to $3 \%$ probability that an earthquake of $M_{\mathrm{j}}=6.6-6.8\left(M_{\mathrm{w}}=6.3-\right.$ 6.4 ) would occur in 30 years could have been forecasted at the Noto Hanto epicentral region if one had used all available data for the evaluation. This is quite unlike the approach used by ERC (2005) to construct their earthquake map of Japan, which takes into account only large earthquakes on long major active faults.

Abundant aftershocks have been recorded along the ENE-striking block-bounding faults, F14, F15, and F16 (Toda, 2008). Focal mechanisms of the moderate-sized aftershocks also suggest that the faulting mechanisms are consistent with the geological structure (figure 2 in Toda, 2008). However, as shown in the most recent tectonic landform and geological profiles obtained from sonic prospecting, there is no clear evidence that such faults and folds (western part of F-15, F16, and N-S-trending folds, etc.) produced any significant deformation during the Holocene. Accordingly, we may interpret the data as indicating that these faults are now inactive with respect to a large earthquakes but that they still react to the coseismic stress changes due to the mainshock and generate small- to moderate-sized earthquakes (Toda, 2008).

Is it appropriate to assume the characteristic earthquake hypothesis for such blind thrust events of moderate size? This question is critical and can introduce uncertainty into the evaluation of seismic risk in regions where both active faults and folds coexist. Even for the 2007 Noto Hanto case, our study shows evidence of both surface-cutting events and significant folding events. It is rational to conclude that the 2007 event justified the evaluation of fault activity by Katagawa et al. (2005). However, the criterion used in their study to identify the most recent activity consisted of a traditional approach to dating the timing and horizon of the fault upper termination, which practically contradicts the blind reverse faulting of the Noto Hanto earthquake. One can argue that there may have been larger events that offset the bottom of the sea floor in the past. Because the fault length is limited in the Noto case, we assume here that surface-cutting process may have occurred only rarely in 2007-type events.

Finally, what are the implications of this earthquake for the strategy of the long-term earthquake forecasting caused by hidden active faults ('gray zone fault'; Okumura, 2005) and offshore faults, which were not incorporated into the ERC strategy? We have indeed seen that the most recent destructive events were associated with shallow $M 6$ class earthquakes that did not expose any evident surface rupture. Perhaps what is most important is to use all available geological and geodetic off-fault information associated with the volumetric extent of the deformation as well as the onedimensional on-fault data. Further, we have to properly evaluate the frequency of $M 6$ events in each region as well as the probabilities of the maximum size events that ERC have already calculated.

Acknowledgments. We wish to thank Hideki Katagawa, Yuichi Sugiyama, Ross Stein, and an anonymous reviewer for their helpful comments and discussion. We are also grateful to JMA and NIED for the hypocenter list.

\section{References}

Awata, Y., S. Toda, H. Kaneda, T. Azuma, H. Horikawa, M. Shishikura, and T. Echigo, Coastal deformation associated with the 2007 Noto Hanto earthquake, central Japan, estimated from uplifted and subsided intertidal organisms, Earth Planets Space, 60, this issue, 1059-1062, 2008.

Geographical Survey Institute, The Mid Niigata prefecture Earthquake in 2004 report index: Results from leveling and GPS-observation, http:// www.gsi.go.jp/WNEW/PRESS-RELEASE/2004/1227-1.jpg, 2004.

Geographical Survey Institute, Coseismic horizontal and vertical displacements due to the 2007 Noto Hanto earthquake detected by the continuous GPS observation, http://www.gsi.go.jp/BOUSAI/isikawa/ tikaku.htm, 2007 (in Japanese).

Geological Survey of Japan, 1:200,000 scale geological map of Nanao and Toyama regions, 1967.

Geological Survey of Japan, 1:1,000,000 scale geological map of Japan, third edition, 1992.

Earthquake Research Committee of the Headquarters for Earthquake Research Promotion, National seismic hazard map for Japan, 121 pp., 2005.

Hodgkinson, K. M., R. S. Stein, K. W. Hudnut, J. Satalich, and H. Richards, Damage and restoration of geodetic infrastructure caused by the 1994 Northridge, California, earthquake, U. S. Geological Survey Open-File Report \#96-517, http://geopubs.wr.usgs.gov/open-file/of96517/fema/html/FEMA.html, 1996.

Japan Meteorological Agency (JMA), CMT solution of the March 25, 2007 Noto Hanto Oki M 6.9 earthquake, http://www.seisvol.kishou. go.jp/eq/mech/cmt/fig/cmt20070325094157.html, 2007 (in Japanese).

Katagawa, H., M. Hamada, S. Yoshida, H. Kadosawa, A. Mitsuhashi, Y. Kono, and Y. Kinugasa, J. Geogr., 114, 791-810, 2005 (in Japanese with English abstract).

Matsuda, T., Magnitude and recurrence interval of earthquakes from a fault, Zisin, Ser. 2, 28, 269-283, 1975 (in Japanese with English abstract). 
National Research Institute for Earth Science and Disaster Prevention, Earthquake mechanism information of the March 25, 2007 Noto Hanto earthquake, http://www.fnet.bosai.go.jp/freesia/event/tdmt/ 20070325091000/update2/index.html, 2007.

Okada, Y., Expected crustal deformation due to seismic faulting, Programme and abstracts, the Seismological Society of Japan, 1992, fall meeting, 240, 1992 (in Japanese).

Okamura, Y., Explanatory notes of geological map west of Noto Peninsula 1:200,000, Marine Geology Map series, 61 (CD), Geological Survey of Japan, AIST, 2003.

Okumura, K., The grey zone of the active faulting, Tottori, Niigata, Bam, and Kobe-un essai, Abstracts of the Hokudan International Symposium on Active Faulting, 114-116, 2005.

Ota, Y., Late Quaternary vertical movement in Japan estimated from deformed shorelines, Roy. Soc. N. Z. Bull., 13, 231-239, 1975.

Ota, Y. and K. Hirakawa, Marrine terraces and their deformation in Noto Peninsula, Japan Sea side of central Japan, Geogr. Rev. Jpn., 52(4), 169189, 1979 (in Japanese with English abstract).

Ota, Y., T. Matsuda, and J. Hirakawa, Active faults in Noto Peninsula, central Japan, Quatern. Res., 15, 109-128, 1976 (in Japanese with English abstract).

Ota, Y., T. Sekiguchi, M. Taguchi, K. Yoshitake, and S. Odagiri, 1:100,000 scale map and explanatory (pp. 16) of crustal movement and land condition map of Noto Peninsula, http://www1.gsi.go.jp/ geowww/themap/pdf/disa-pdf/d1347.pdf, 1998.

Research Group for Active Faults in Japan, Active Faults in Japan, sheet maps and inventories, rev. ed., 437 pp., Univ. of Tokyo Press, Tokyo, 1991.

Sagiya, T., S. Miyazaki, and T. Tada, Continuous GPS array and presentday crustal deformation of Japan, Pure Appl. Geophys., 157, 23022322, 2000.

Schwartz, D. P. and K. J. Coppersmith, Fault behavior and characteristic earthquakes: Examples from the Wasatch and San Andreas fault zones, J. Geophys. Res., 89, 5681-5698, 1984.

Stein, R. S. and G. Ekstrom, Seismic and geometry of a 110-km-long blind thrust fault 2. Synthesis of the 1982-1985 California earthquake sequence, J. Geophys. Res., 97, 4865-4883, 1992.

Toda, S., Coulomb stresses imparted by the 25 March $2007 M_{\mathrm{w}}=6.6$ Noto-Hanto, Japan, earthquake explain its 'butterfly' distribution of aftershocks and suggest a heightened seismic hazard, Earth Planets Space, 60, this issue, 1041-1046, 2008.

USGS, Magnitude 6.7-near the west coast of Honshu, Japan 2007 March 25 00:41:57 UTC, http://earthquake.usgs.gov/eqcenter/eqinthenews/ 2007/us2007aiae/, 2007.

Wallace, R. E., Earthquake recurrence intervals on the San Andreas fault, Geol. Soc. Am. Bull., 81, 2875-2890, 1970.

Wells, D. L. and K. J. Coppersmith, New empirical relationships among magnitude, rupture length, rupture width, rupture area, and surface displacement, Bull. Seismol. Soc. Am., 84, 974-1002, 1994.

S. Toda (e-mail: s-toda@aist.go.jp) and Y. Awata 